\title{
IDENTIFYING BARRIERS FOR WOMEN PARTICIPATION IN COMPUTER SCIENCE
}

\author{
Maria KORDAKI ${ }^{1}$, Ioannis BERDOUSIS ${ }^{2}$ \\ ${ }^{1}$ Associate Professor, Dept of Cultural Technology and Communication, \\ University of the Aegean, ${ }^{2} \mathrm{PhD}$ Candidate, Dept of Cultural Technology and \\ Communication, University of the Aegean, \\ GREECE. \\ E-mail: ${ }^{1}$ m.kordaki@aegean.gr, ${ }^{2}$ i.berdousis@aegean.gr
}

\begin{abstract}
This study focuses on the development of a framework for the identification of main barriers that discourage women to pursue Computer Science (CS) as their University studies and their careers options. The proposed framework is based on the analysis of secondary data emerged from the research literature. In fact, a large number of papers were qualitatively analyzed and the themes who act as barriers for women participation in the CS scientific field and career were estimated. The analysis of the data identifies as essential barriers: school, family, computer games, role models, peers and work culture, stereotypes and communication of stereotypes. All these barriers form a model that seemed to shape females' perceptions, attitudes, interest, confidence and career decisions regarding CS education and career choices. Based on the aforementioned barriers, proposals for future research dimensions and suggestions for the treatment of the phenomenon of females' under-representation in CS education is given.
\end{abstract}

Keywords: barriers; Computer Science; females; gender representation; model;

\section{INTRODUCTION}

Women have been pioneers in the evolution of CS, and their stories need to be known more widely. They have passionately programmed computers for many decades. As far back as 1843, Ada Lovelace wrote programs on Charles Babbage's mechanical computer while in 1946 six women mathematicians, known as human 'computers' -Fran Bilas, Betty Jennings, Ruth Lichterman, Kay McNulty, Betty Snyder, and Marlyn Wescoff- created working programs for the ENIAC computer during the Second World War. Even later, Grace Murray Hopper played a key role in creating COBOL and standardizing FORTRAN - named as the Data Processing Management Association's first 'man of the year' in 1971 (Misa, 2010a). According to Misa (2010b), in the 1950s the pioneering generation of CS featured a surprising number of prominent women who led research teams, defined computer languages and even pioneered the history of CS. In the 1960s, women entered the emerging CS profession in unusually large numbers. Despite these early successes, in the late-1980s women stop entering CS in large numbers, and the proportion of women studying CS actually began falling dramatically - and it has continued to do so, steadily, until to date (Camp, 2012). Despite the shrinking representation of females in undergraduate studies and in CS workforce, the proportion of women at higher ranks -doctorates and faculty- have continued to grow overall. 
Abbate (2010) attributes women under-representation in CS to the entry requirements that CS departments instituted -in the mid of 80's- which ultimately favored males, in an attempt to reduce the number of their students. However, C. C. Hayes (2010a) claims that unattractive stereotypes about CS scientists started to become established, affecting more females than males. Here it is worth mentioning that, research has identified several reasons to justify why increasing the participation of women (and other underrepresented groups) in CS is crucial. Camp (2012), advocates that when it comes to the underrepresentation of women, being educated in CS, three critical issues emerge. These issues concern the labor shortage and huge demand that exists for people trained in CS, the need for diversity in the workforce to innovate higher quality technologies and the goal of equal opportunity.

In fact, when it comes to females in CS, their underrepresentation is an alarming issue for both; the USA and the EU. A sizable, diverse and creative CS workforce is critical for continued participation in the high-tech, global economy (C. C. Hayes, 2010b). Failing to capitalize on the talent of women in CS may threaten productivity, innovation and competitiveness (Ashcraft et al., 2012; Hill et al., 2010). Attracting more women into CS will not just help to address a problem that risks damaging the whole economy and failing to reflect our diverse society, but also contributes to realizing goals for equal opportunities and empowers women by enhancing their capacity to participate fully in the information society and shape its development (Ashcraft et al., 2012). With technology playing an increasingly crucial role in all of our lives, having more people from different backgrounds in its creation can help break down gender inequalities (Ashcraft et al., 2012).

The under-representation of females in both CS education and the workforce in several countries has motivated excessive research, documenting the necessity of increasing females' representation and identifying those essential factors influencing females' participation in CS. Thus, it is crucial to capitalize on previous research findings towards the development of a model that reflects the essential barriers for women participation in CS which have been reported till now in the literature. This is the contribution of this paper.

Thus, in the next section of this paper, some essential barriers for women participation in CS are reported, namely: school education, families, computer games, role models, peers and work culture as well as society in terms of negative stereotypes and their communication through media and people. Finally, a model reflecting all the barriers emerged from the literature is proposed and conclusions and future research directions are drawn.

\section{IDENTIFYING BARRIERS:}

\section{WHY WOMEN DO NOT PARTICIPATE IN COMPUTER SCIENCE}

Over time, several studies have identified numerous key social and structural factors that influence girls' participation in CS, often deterring them from choosing future education or careers in technology (Ashcraft et al., 2012; Barker \& Aspray, 2006; Gürer \& Camp, 2001; 2002). These factors are addressed below.

\section{School Education}

Concerning school education, some key factors contributing to loss of interest, -not just for girls- in CS are: (a) the curriculum with no relevant connection, (b) the teaching practices that discourage collaboration and some pedagogies that, mainly, rely on lecturing, (c) teacher stereotypes, and (d) uncomfortable learning environments discourage girls' participation fading out their interest. 
Curriculum. Some studies indicate that CS courses, and the way these are taught, make CS curriculum irrelevant, encouraging negative perceptions, deterring girls from taking these courses (Margolis, 2010; Ashcraft et al. 2012). When CS is taught in the abstract, students cannot recognize how technology can help address social problems. This approach also reinforces a view of CS as a lonely, isolated, machine-focused field (Margolis, 2010; Papastergiou, 2008). Female secondary students also identified two key factors for not taking CS courses: (a) 'the subjects are boring', and (b) 'the subjects would not be helpful to me in my chosen career path' (Anderson, Lankshear, Timms, \& Courtney, 2008, p. 1310).

Teaching practices. CS classrooms teachers in both; secondary and tertiary level often favor independent work and discourage collaborative work as well as do not give the chance to students to take risks or make mistakes (Margolis, 2010). However, research has revealed positive effects of collaboration for girls (Werner \& Denning, 2009). In addition, instead of traditional lecturing teaching active, hands-on, project-based learning approaches play a key role in attracting girls in CS undergraduate studies too. As for example, males seemed to prefer the traditional computer based computer programming module, while girls performed better when the teaching emphasized the use of some principles of physical CS, in order to take computational concepts out of the screen and into the real world so that students interact with them (Rubio, Romero-Zaliz, Mañoso, and Angel, 2015).

Teacher stereotypes. What is more, teachers often have the tendency to assume that, while girls work hard, boys have innate talent for CS, are more natural with the computer and have more interest (Margolis, 2010). That unconscious biases about who has a flair on CS are crucial since perceived support from teachers affects girls' interest in CS classes and CS careers (Denner, 2011).

Uncomfortable learning environments. Societal beliefs about CS as a masculine field are present and disseminated in CS classrooms (Margolis, 2010). CS classrooms are also often dominated by boys and girls often experience then as uncomfortable and unwelcome environments (Goode, 2007).

\section{Families}

Families seem to play a crucial role in girls' engagement in CS (Ashcraft et al., 2012). The parental influence, regarding parental expertise or career in CS along with their support and encouragement, as well as girls' early exposure to Computers and CS at home are considered as key factors in affecting girls' interest in CS.

Parental Influence. Parents have significant influence as role models and in the types of messages or beliefs they communicate to girls both implicitly and explicitly (Liston, Peterson, \& Ragan, 2007). Parental expertise or career in CS can play an important role in influencing girls' perception on the CS field. On the other hand, research suggests that parental or familial support, advice and encouragement to pursue CS seem to be decidedly important. In some cases, parents unintentionally provide obstacles for their own daughters and through subtle biases provide more support for their male children (Gürer \& Camp, 2002). Perceived parental encouragement and support had a powerful impact on girls' interest in CS (Denner, 2011) as well as on the completion of their CS studies and choose a CS career (Guzdial, Ericson, McKlin, \& Engelman, 2012).

Early Exposure to Computers. Abbate (2010) argues that one of the primary reason for females' under-representation in CS is their lack of experience. She maintains that as college students flocked to CS in the mid-1980s, depts tried to reduce the numbers to a manageable size by instituting entry requirements that favored candidates with prior 
computer experience, discouraging those students who had less experience or confidence. As a result, fewer women than men have been admitted to CS. The gendered effects of these changes were probably unintentional, but true. There are also studies emphasizing on the role of the early exposure to computers and CS, pointing out that a crucial factor is the kind of CS experience to improve success in future CS classes (Barker \& Aspray, 2006). Early exposure to CS seems to favor boys, as research found that more boys than girls used computers at home, boys began using computers earlier, and boys used their computers at home on average more hours per day than girls (Barker \& Aspray, 2006). Opportunities for early familiarization of students with computers at home acknowledged as key factor differentiating boys' and girls' motivation for studying CS (Papastergiou, 2008). Even if computer use and early exposure in CS is a key factor influencing children's choices and perception about CS, the 'creative production rather than just use' of technology in home seems to be another important factor in later success in CS courses (Barron, 2004). More boys than girls had that kind of experience. Interestingly, in most cases - apart from programming courses - girls and boys in the same 'experience level' had no differences in the confidence, interest or motivation. Camp (1997) also asserts that access to computers and training in the concepts of CS should be provided at preschool levels in order to give women the greatest chance to avoid developing insecurities about their abilities.

\section{Computer Games}

Unfortunately, the majority of computer games target the boy market. Stereotypical representations and narratives are present in many computer games (E. Hayes, 2008). Moreover, many games created for girls reinforce stereotypes about the kinds of things girls are interested in (E. Hayes, 2005). The boy-dominated characteristics -shooting, violent graphics, loud noises- do not appeal to girls who tend to prefer games that encourage collaboration with other players and involve storylines and character development with female characters (Gürer \& Camp, 2002). Some studies, also, suggest that the games addressed to boys usually allow users to make programmatic modifications, which directly develop actual CS or programming skills, encourage online communities where boys interact, exchange knowledge with other players and gain more advanced skills (E. Hayes, 2008). However, research indicates that, intervention programs using games to increase girls' interest in CS can have positive effects (Werner, \& Denning, 2009). Taking this into account, games can be a promising way of making CS classes more relevant for boys and girls and integrating them early in actual CS activities (E. Hayes, 2008). Understanding fully the gaming practices of girls and how they learn CS concepts through these practices can held the better design of that programs (Denner, 2011).

\section{Role Models}

Research in CS education finds that role models are important factors influencing girls' decisions to pursue CS (Barker \& Aspray, 2006; Cozza, 2011; Gürer \& Camp, 2001; 2002; Townsend, 2002). Girls and young women need women role models in CS related professions who can inspire interest in CS careers and demonstrate to them that computer scientists have whole and satisfying lives inside and outside the workplace (Gürer \& Camp, 2001). One of the most important characteristics of a woman-role model is that girls perceive these role models as 'relatable' and similar to themselves. This perceived similarity to people in the field and a feeling that one will 'fit in' is a crucial factor in pursuing a CS career (Cheryan, Siy, Vichayapai, Drury, \& Kim, 2011). There can be many types of role models, family members, teachers, faculty members and colleagues. Girls can interact with women 
computer scientists online or in person or learn about their stories through biographies and talks (Townsend, 2002) Female faculty in Computing depts provide the most appropriate form of mentoring for female students (Carrington, Tymms, \& Merrell, 2008). The absence of female faculty in CS dept may deter young women from retaining in the field; depts with no female faculty lost female students at high rates relative to men while CS depts with a higher number of female students retained them at most (Cohoon, \& Aspray, 2006).

\section{Peers and Work Culture}

Peers can have a powerful influence on children's beliefs and behavioral choices (Barker \& Aspray, 2006). Peer influence is really strong during school years, as students need to ensure acceptance of peers (Barker \& Aspray, 2006). Girls' intention to pursue CS can be positively affected by the perceived support of peers and school peers as well as real life examples of girls interested in CS (Denner, 2011; Cozza, 2011). Cozza (2011) also noted that, boys and girls consider peers as guides, especially when they lack adult mentors or role models. However, peer influence can have a negative effect on girls' perceptions and interests if their peers are not interested in CS. Girls' interest in CS classes was affected by the perception of the climate of these classes and the possible dominance of boys in the labs (Jenson, De Castell, \& Bryson, 2003). In addition, girls in all -or mostly- boys' environments may feel uncomfortable being the only girl in the class. However, research has shown that, often, single-sex education can benefit girls since that set classroom discourses free from male domination, diminish gender-related perceptions and tensions and increase girls' confidence and interest in CS (Barker \& Aspray, 2006; Gürer and Camp, 2002).

As far as the workplace environment, peers influence seems to be crucial for women's decision to stay in CS. Women cited feelings of isolation, unsupportive work environment, extreme work schedules, unclear rules about advancement and success, sexist humor and macho work culture as major factors in their decision to leave the CS industry (Cohoon, \& Aspray, 2006). In addition, the conditions in the computer-game industry remain overtly hostile to female employees (Jenkins \& Cassell, 2008). Misa (2010a) also noted that there has been a gender-specific tail-off in the CS workforce, where women leave the workforce in the middle of their career. That mid-career exit was not a result of women's choices, because they actually chose that profession, but women were pushed by 'macho work environments, serious isolation, and extreme job pressures' (Misa, 2010a, p. 6). However, Abbate (2010) interviewed successful women in CS and provide clues describing CS not merely as a field where women can just survive, but one where 'stereotypes lose their sting', and work is both challenging and social while the focus on just negatives, deters many women from considering a career in the field.

\section{Stereotypes}

Most recent studies argue that one novel and powerful social factor that may perpetuate the under-representation of women and girls in CS is the stereotypes about the culture of the field (Cheryan et al., 2015; Cheryan, Plaut, Davies, \& Steele, 2009). Cheryan et al. (2015) argue that stereotypes about CS act as 'educational gatekeepers', preventing females from joining the CS field. They support that students espouse several stereotypes about the culture of CS while girls face negative stereotypes about their abilities. Both sets of stereotypes may be operating simultaneously to make girls feel like they do not belong in the field of CS.

About the culture of the field. Research has found that stereotypes about computer scientists lower high-school girls' interest in CS (Master, Cheryan, \& Meltzoff, 2014). 
Specifically, computer scientists are stereotyped as: (a) males technology-oriented with strong interests and high skills in programming and enjoy tinkering with electronics (Cheryan, Meltzoff, \& Kim, 2011), and little interest in people (Diekman, Brown, Johnston, \& Clark, 2010; Margolis \& Fisher, 2003), (b) 'geeky guys' so obsessed with technology that they are singularly focused on computers and programming, to the exclusion of other interests (Beyer, 2014), (c) lacking interpersonal skills and being socially awkward (Mercier, Barron, \& O'connor, 2006). Undergraduate students (Beyer, 2014; Margolis \& Fisher, 2003), high school students (Schott \& Selwyn, 2000), even middle school students are aware of this stereotype (Mercier et al., 2006), (d) males ( Mercier et al., 2006), (e) having masculine interests -such as liking science fiction and playing video games- that may lead some women to question whether they belong in the field of CS (Cheryan, Meltzoff, et al., 2011), (f) 'intelligent', 'geniuses' and 'logical' (Beyer, 2014) while CS is seen as requiring an inborn 'brilliance' to be successful in the field (Leslie, Cimpian, Meyer, \& Freeland, 2015). The pervasive stereotype of computer scientists as being nerds or geeks further conveys the notion that they are smart (Schott \& Selwyn, 2000), (g) males who are 'unattractive', 'pale', 'thin', 'wearing glasses' (Mercier et al., 2006). Stereotypes of computer scientists' physical appearance may deter women more than men (Margolis \& Fisher, 2003).

The work in CS is also seen as isolating and relatively dissociated from communal goals such as helping society and working with others (Diekman, Brown, Johnston, \& Clark, 2010). The pervasive image of the solitary male programmer, so wrapped up with CS as to be 'dreaming in code,' is not universally attractive or inviting. In fact, in today's society, CS stereotypes are perceived as incompatible with qualities that are valued in women, such as being feminine, people-oriented, and modest about one's abilities (Leslie et al., 2015). As a result, when these stereotypes are prominent, females fell less belonging in the field (Cheryan et al., 2009; Master et al., 2014). The less that students feel a sense of belonging in a field, the less likely they are to pursue that field (Master et al., 2014).

About girls' cognitive abilities. Stereotypes about girls' math abilities 'girls are not good at math' are negative (Cheryan et al., 2015). This stereotype may affect female students' test performance as well as their self-confidence deterring them from pursuing a career in science. However, difference in average math performance between girls and boys no longer exists in the general school population ( Hyde, Lindberg, Linn, Ellis, \& Williams, 2008). Actually, girls and boys tend to have different cognitive strengths and weaknesses (Hill et al., 2010). Boys seem to perform better on tasks using spatial orientation and visualization and on certain quantitative tasks that rely on those skills. However, research shows that individuals' spatial skills consistently improve dramatically in a short time with a simple training course (Hill et al., 2010). Girls outperform boys on tests relying on verbal skills, writing, as well as in tests involving memory and perceptual speed (Hill et al., 2010).

Ceci et al. (2009) reviewed more than 400 articles exploring the causes of women's under-representation in STEM fields (including CS), referring to biological - as well as to social - factors, and concluded that the research on sex differences in brain structure and hormones is inconclusive. Ceci et al. (2009) suggest that males and females use different parts of their brains to complete the same tasks. They conclude that 'men and women achieve the same general cognitive capability using somewhat different brain architectures' (Ceci et al., 2009, p. 236). Overall, studies of brain structure and function, hormonal modulation, human cognitive development, and human evolution have not found any significant biological difference in men's and women's ability to perform in science and mathematics 
(Ceci \& Williams, 2007). The absence of negative stereotypes about girls' abilities and the thought they can make it can increase their confidence and interest in science fields (Hill et al. 2010).

\section{Communication of stereotypes}

The stereotypes about the culture in the field of CS are communicated, perpetuated, and transformed through media, people in the field, and the school environment. These stereotypes could be changed by trying to diversify the images of CS.

Media. Several studies have investigated the way in which CS and technology are portrayed in a variety of media texts (Misa, 2010a) and found prevalent gender stereotypes about people in CS. Tympas, Konsta, Lekkas, and Karas (2010) examined the construction of gender and CS through advertising images. They examined $1500 \mathrm{CS}$ advertisements and they pointed out that in these advertisements, there is no shortage of women; but there is a very strong gender stereotypical pattern in how women are shown with computers and what they are shown doing with them: (a) women do the Computing work; they are working at the keyboard-input and the printer-output parts of computers. They are- fully engaged with the standardized, routine, digital side of CS, the office working of CS, that awaits passive computation, (b) men are not working with the computer; they are in control of the CS work. In this case the image on the computer screen was changed from a female eye or face to a financial or engineering chart.

In fact, men are placed at what has always been the expensive side, that of the analog Computing that is required to actively produce the Computing analysis. This follows a historically deep pattern of imaging men as 'analysts' and women as 'computors'. This pattern is also broken only when the sitting male was a student of a standing female teacher. In this case women were depicted as providing education to boys and only rarely to adult men. However, advertisements of vocational computer schools show women to teach students to be proficient at routine data-entry jobs using generic computers and men to teach computer programming often with an interesting variety of computers.

Advertising, and other media have played a large role in establishing, spreading, and perpetuating images of men as the decision makers, experts, and innovators in CS, and women as 'computer phobes' or users who merely execute the instructions of men (Tympas et al., 2010). Media still portrays gender stereotypes and of computer professionals as geeks without social skills doing boring and solitary jobs (Ashcraft et al., 2012; Cheryan et al., 2015), while women are represented as holding little power or understanding of technology and being passive individuals (Cozza, 2011). The power of media to alter the perceptions concerning gender stereotypes in CS can be confirmed by the progress that have been made in portrayals of other - once male-dominated - fields. Once established, the stereotypes became self-fulfilling prophecies by rendering invisible the people who did not fit the stereotype, such as female computer users and the large number of computer- phobic males.

People in the field. People in the CS field (CS professionals, school teachers and students) embody certain characteristics, habits, and belief systems that can signal what is normative and valued in the field. Cheryan, Siy, et al. (2011) experimented how people embodying CS stereotypes can influence women's interest to CS. Results showed that women who interacted with the stereotypical actors were significantly less interested in majoring in CS than those women who interacted with the non-stereotypical actors, while this effect endured for 2 weeks after the interaction and was equally strong regardless of whether the actor was male or female (Cheryan et al., 2013). When the people in CS depict 
themselves in a manner consistent with the stereotypes, it can convey to other students that one must fit the stereotypes to be successful in this field.

School Environment. School environment that fit CS stereotypes and are compatible with characteristics, interests, and values associated with males are likely to deter females from CS (Cheryan et al., 2015). Cheryan et al. (2009) studied how objects in a CS class can influence undergraduates' interests to CS. Women in the room that did not contain the stereotypical objects (Star Trek poster, comics, videogame boxes, soda cans, electronics, software, computer parts and technical books and magazines) expressed significantly more interest in majoring in CS than those in the room that did fit the stereotypes (nature poster, neutral books, water bottles, healthy snacks, general interests books and magazines). For men, the environment did not affect their interest in CS. Similar results came up when undergraduates were asked to join an online educational environment as well as an introductory CS course (Cheryan, Meltzoff, et al., 2011; ). In both cases females reported a lower sense of belonging in the stereotypical environment. In contrast, men reported an equal, and sometimes greater, sense of belonging in the stereotypical environment than the non-stereotypical one. Studies with high-school students had also similar results.

Diversifying the images of CS. If the popular image of the CS field is a significant factor in widening the gender gap, then diversifying the popular images may be a crucial strategy. While, it may be difficult to erase the already established stereotypes, multiple images and possibly contradicted stereotypes can coexist (Misa, 2010a) as for example, computer scientists as 'evil hackers', 'whiz-kid nerds', and the twenty-something entrepreneur-millionaires (C. C. Hayes, 2010b). Fortunately, people can hold multiple, possibly conflicting images of a single profession, simultaneously. Actually, in some cases, stereotypes of computer scientists can be a source of pride, identification, and belonging for some in the field. It is widely acknowledged, that there is a large number of students who may be drawn to these fields because of these stereotypes (Cheryan et al., 2015).

By diversifying the image of the CS field, students who are interested will not think that they must fit a specific mold to be successful. Diversifying the image of CS may not only attract more women in the field, but also make a more comfortable environment for men because some of them seemed to prefer the non-stereotypical environment over the stereotypical one (Cheryan et al., 2015). What is more, some men also highly value opportunities to work with and help others (Diekman et al., 2010). Attracting more men that do not fit to the 'computer scientist stereotype' is a way to stretch stereotypes and diversify the field.

Cheryan et al. (2015) state that females to date are exposed to an image of CS that is not realistic and does no depict CS in full extend. This image presents CS cultures as fitting a narrow profile. A broader image that shows many different types of people and working environments in CS represents a more realistic portrayal. Cheryan et al. (2015, p.6) believe that 'once we start the process of welcoming more women and girls (into CS), the process of culture change will likely build on itself and contribute to further improving the actual and perceived culture of these fields for women'. They believe that we have to encourage diversity of backgrounds and ideas. Here, it is worth noting that there are at least two successful real-world examples of CS depts at -Carnegie Mellon and Harvey Mudd - that increased the proportion of women majoring in CS by changing stereotypes of CS in addition to structural changes. These changes involved: use of diverse role models, keeping high admission standards, but adding an emphasis on leadership qualities and dropping the 
requirements for prior programming experience as well as exposure of students to a variety of CS applications and reforming some introductory CS courses by adding a few 'catch-up' courses to the curriculum to level out background differences so that CS not seen as a 'geeky, know-it-alls' field (Cheryan et al., 2015; Margolis \& Fisher, 2003). None of these changes were gender specific, but after implementing them the dept increased the percentage of women students from less than $10 \%$ to more than $30 \%$, and greatly changed the culture.

\section{Girls' Perceptions, Interest, Confidence, Attitude and Career Choices in CS}

Girls' perceptions, interests, confidence, attitudes and career choices are shaped by the larger society and local environments in which they learn about CS and technology, and this significantly influences what appears to be their 'choices' to pursue CS studies careers. The aforementioned factors preclude women from being able to make a truly 'free' choice (Ceci et al., 2009). Girls do not come by these perceptions, interests, and career decisions innately or develop these beliefs and perceptions in a vacuum. Recent research indicate that girls and boys perform in CS at comparable levels, when they realize similar training and experience, showing no innate reason boys would be better at technology (Voyles, Haller, \& Fossum, 2007). In a study conducted in Greece, Ilias and Kordaki (2006) studied 1957 degrees earned by Computer Engineers and revealed that, in terms of achievement, there were no significant differences between male and female graduate computer engineers.

Perceptions of CS. Girls, even boys, either have very limited knowledge or inaccurate perceptions about what CS careers involve and what CS professionals do (Carter, 2006). The stereotypes about the culture of the field are still predominating in girls and boys. They perceive CS as a field dominated by genius male computer hackers who spend a great deal of time alone on the computer, working or playing games, have an inadequate social life, enjoy hobbies involving science fiction and wearing glasses and lab coats. They also perceive CS careers as having little or no interaction with others and that CS professionals are obsessed with computers (Anderson et al., 2008; Papastergiou, 2008).

Interest in CS. One of the basic motivators for girls' and boys' decisions to pursue CS studies is their interest in CS as a subject (Tsagala \& Kordaki, 2007; 2008). Nevertheless, girls and boys are not equally interested; even interest varies among girls already interested in science. Despite the fact that a considerable percentage of girls seemed to express interest in CS and STEM fields it doesn't necessarily translate into choosing one of these fields for a career. As one of the contributing factors to the interest of girls in CS is the extent to which they see the value and their relevance in CS (Denner, 2011) including a belief that one can succeed in that occupation (Hill et al., 2010). Compared to girls who were not interested in STEM fields, girls interested in STEM fields were higher achievers, better students, had stronger support systems, had higher confidence in their academic abilities, have higher academic goals and aspirations for themselves, had been exposed early to STEM fields, had more career support from parents, family members, teachers, and friends, and have had greater exposure to STEM fields. Changing girls' limited knowledge and inaccurate perceptions of CS is vital for increasing their interest.

Confidence. Gürer and Camp (2002) argue that self-confidence is influenced and formed by four different components: performance and accomplishments, observing and learning from others, freedom from anxiety concerning work and conduct in a particular field, as well as persuasion and support from others. Boys have expressed higher levels of confidence with computers (Barker \& Aspray, 2006) while most male students seem to believe that they are better than their female classmates (Sieverding \& Koch, 2009). 
Contrarily, girls mostly express lower levels of confidence, rating their ability lower than boys, even when actual achievement levels are similar (Ashcraft et al., 2012). Even female CS majors found that they had less confidence than did male non-majors (Beyer, 2014).

Experience with computers seems to be a critical factor influencing girls' confidence in CS (Guzdial et al., 2012). However, research argues that girls are entering introductory CS courses at universities with less experience than boys (Cohoon \& Aspray, 2006). The prior knowledge that CS programs assume for their students, that girls may have not obtained, can be considered as lack of ability or interest, discouraging females (Gürer \& Camp, 2002). However, students with equal levels of programming experience, perform at the same level (Bruckman et al., 2009). Despite that fact, girls often evaluate their own abilities lower than do boys with same levels of experience (Guzdial et al., 2012).

Encouragement seems to be another important factor affecting females' selfconfidence and a decisive factor for them to choose a CS major or career (Guzdial et al., 2012). The importance of encouragement from parents, teachers, and other influencers is a very consistent finding across studies and it is promising for the design of interventions aimed at increasing females' participation in CS (Ashcraft et al., 2012).

Attitudes. Gürer and Camp (2002) argue that positive attitudes towards CS can greatly influence the success of a female-student and also whether she continues in CS. Students in elementary school seem to have positive attitudes toward computers, but it is later that gender differences in attitudes become pronounced. Nevertheless, the majority of studies, presented in the literature review of Gürer and Camp (2002), have shown that boys and girls who spend more time with computers have a more positive view of CS. However, girls' and boys' gender-stereotyped views on computers were not related to their computer attitudes (Meelissen \& Drent, 2008). The intensity of computer use and self-efficacy beliefs in the computer use has also a positive effect on students' computer attitude.

The use of computer outside school hours has a positive effect on the computer attitude of boys but not on that of girls. Compared to girls, boys report considerably more frequent computer use outside school hours and judge their self-efficacy in computer use more positively. Boys with more confidence in their abilities had more positive attitudes toward computers. Gender differences in computer attitude seemed to be related to gender differences in students' perceived encouragement by parents about computers and CS. The pedagogical approach followed in school seemed to have no particular influence on boys' computer attitude, while girls seemed as influenced by a student-oriented pedagogical approach.

Women seemed to have lower but not negative computer attitudes than their male counterparts (Sáinz and López-Sáez, 2010). The fact that boys and girls exhibit different computer attitudes could entail that they differ in their motivations and interests in considering the utility of computers, as well as the role that computers play in their lives. It is also claimed that girls hold more positive attitudes about CS professional's social skills while boys hold more positive attitudes about CS professional's intellectual aptitudes than their female counterparts (Sáinz and López-Sáez, 2010). Overall, many women want to use computers as to make society better, and to 'do good' in the world, use CS for medical purposes, communication, and solving community problems over CS for the sake of CS, developing better computers, or programming for games, whereas boys prefer to show CS as a tool to help them be in control of their own lives (Margolis, \& Fisher, 2003). Finally, women's negative computer attitudes have been associated with their scarce representation in 
technology and CS studies (Anderson et al., 2008). However, it is plausible that the influence of the above-mentioned factors on computer attitude is reciprocal: the more positive the computer attitude of a student, the more interested he / she will be in using computers and trying (new) computer applications, resulting in an even more positive attitude toward computers. Because girls show lower intensity and lower self-efficacy in computer use than boys, these reciprocal relations may increase gender differences in computer attitudes in the long term. Thus, gender differences in computer attitude may increase with age.

Career choices. Boys and girls pursue a CS major or career for several reasons. Sometimes they are different but in some cases there are similarities. The most important reason boys chose a CS major was interest in computer games while, the most important reason girls chose a CS major was their desire to use computers in another field (Carter, 2006). Interestingly, the most important reason, for both girls and boys, for not choosing a CS major was the lack of desire to sit in front of a computer all day. Guzdial et al., (2012) found that the 3 top reasons for choosing a CS major are the same for both males and females, namely: interest in computers, rich opportunities and financial gains. Concerning the reasons for choosing a CS career, both girls and boys placed a high value on communal career characteristics, like 'having the power to do good', 'doing work that makes a difference', higher than having a prestigious and secure career or a creative and innovative career (Guzdial et al., 2012). Basic motivating factors for females were an interest in CS as a subject, job security, interest in helping people or society and good living examples, such as charismatic teachers, successful family members in CS and mentors projected by the media (Tsagala \& Kordaki, 2007). Basic motivators for males included an interest in CS as a subject 'interest in computer games', 'interest in solving problems with Computing,' and 'liking to program computers', rich employment opportunities, financial gain and experience with computers (Tsagala \& Kordaki, 2007).

More males than females imagine their future after studying CS to be in a profitable career in the Computing Industry, while a considerable percentage of females expressed an interest in a CS-based career to attain job security, mainly in the public sector (Tsagala \& Kordaki, 2008). School seemed to positively affect the decisions of more females than males in choosing studies in CS. Friends can also affect students' choices. Friends seemed also explicitly to affect, males' more than females' choices (Tsagala \& Kordaki, 2007). Furthermore, the most influential factors -among 91 factors- to pursue a CS degree, were: social encouragement, self-perception, academic exposure to computers and CS, and CS career perception (Wang, Hong, Ravitz, and Ivory, 2015) .

\section{IDENTIFYING BARRIERS FOR FEMALE PARTICIPATION IN CS: A MODEL}

Based on all the above a model identifying essential barriers for female participation in CS is presented in Figure 1 and is briefly summarized below.

Education: Formal education can be a factor contributing to the low representation of females in CS negatively affecting, in some cases, their interest in the field. Irrelevant curriculum with no connection to real life, teaching practices that discourage collaboration and teachers with (un)conscious bias about girls' abilities and the culture of the field are basic aspects of school education that may deter girls, from pursuing CS. The unwelcome environment in a CS class, -dominated by boys- also reinforces the loss of girls' interest. 


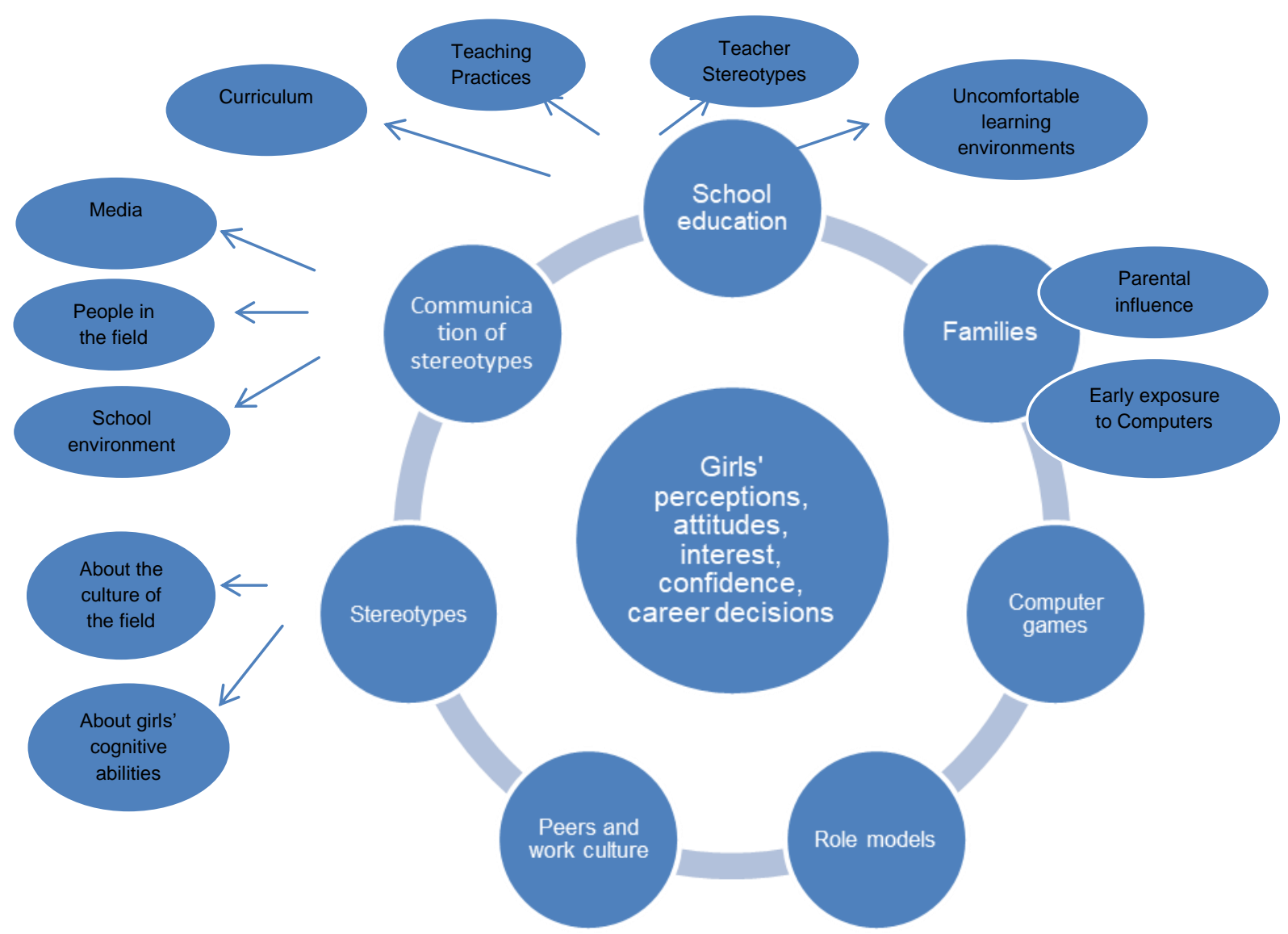

Figure 1. Key factors that influence women's participation in Computer Science

Families: families can play a significant role in girls' and boys' decision about pursuing CS. The parental - or familiar - expertise or career in CS can play a role, but the parental support and encouragement, the early exposure to computers and CS at home and the kind of computer experience have a decidedly powerful impact on girls' choices to persist.

Computer games: These, which are often children's first introduction to CS activities, seemed to deter girls from computers, because these are designed mainly for male audiences with stereotypical representation. The opportunity for programmatic modification and other kinds of computational interactions may also foster mainly boys' interest in CS. Nevertheless, the rise of appropriate gaming, influencing girls' participation in CS is worth of further research.

Role models: It seems that the existence of females in the CS field can inspire women, improve their self-efficacy, and reverse negative stereotypes as they can realize -through real life examples- that they can pursue, persist, 'fit in' and succeed in CS.

Peers and work culture: Peers, at school and at work, influence females' decisions and choices. Peer influences can have a positive effect on girls' plans to pursue CS or women's decision to persist. Peers can also negatively affect girls' choices and decisions if their peers are not interested in CS. A possible solution to that may be single-sex environments that can boost the positive aspects and mitigate some of the negative aspects of peer influences. 
Stereotypes: Even if there is not clear evidence that one of the two sexes is smarter than the other, the belief that girls' cognitive abilities lag behind boys' prevails. That stereotype affect girls' performance and self-efficacy deterring them from choosing science and CS. What is supposed to be a 'free' choice is unconsciously guided by that stereotype as well. In the absence of that stereotype girl gain on confidence and perform equally well as boys.

Communication of stereotypes: The stereotypes about the culture of CS -people in the field, work, and values- and the abilities of girls are communicated through media, people in the field, and the school environment. Media and popular culture -persisting on a small percentage of CS jobs- present CS as masculine and geeky. The different images impact our ideas and our ideals, including whom we see as qualified for CS work when we see certain kinds of people doing certain jobs. But media also have the power to alter the stereotypes if someone see the progress has be done in portrayals of other occupations. Moreover, people in the field with their characteristics, their habits, and their beliefs, as well as a school environment that reflects all the stereotypes can discourage women from CS. Diversifying the popular images of the CS field seems to be a promising strategy. In that way we can attract women, as well as men, in the field who are interested and have not to believe that they must not adapt to a certain matrix to be successful. In addition to diversifying the field, men free of stereotypes in CS can favor a progressive mitigation of the negative stereotypes.

\section{CONCLUSION}

Concluding on all the above, it seems that, girls' perceptions and interest in CS, confidence and perceived ability, attitudes towards CS as well as study and career choices are influenced and shaped by the larger environment they learn about CS, especially by the factors described above, namely: school education, family, computer games, role models, peer and work culture, stereotypes and communication of stereotypes by the Media, people in the field and school context. Girls' perceive CS as mainly masculine field, because of the limited knowledge or inaccurate perception they have about the field, mainly shaped by the images projected by the media, deter women from the field. Enriching and diversifying the images of CS, can foster girls' interest in the field, as this interest can be shaped by the extent to which they see the value and relevance in CS as well as by their belief that they can succeed in that. However, girls express less confidence and rate their abilities lower than boys even when actual achievement levels are equal.

Experience can play an important role reinforcing their self-confidence, while encouragement by family, school and peers can mitigate differences in levels of selfconfidence and perceived ability. Moreover, positive attitudes toward CS can greatly influence girls' pursue of a career in the field. These attitudes are shaped by the barriers discussed above and mainly, experience, self-efficacy, encouragement, stereotypes and preferences. Finally, females' CS career and study choices are shaped by the majority of factors discussed so far, but it seems that key influential factors are: social encouragement, self-perception, experiences with and exposure to CS activities, and career perceptions. 


\section{BIBLIOGRAPHY:}

[1] Abbate, J. (2010). The pleasure paradox: Bridging the gap between popular images of computing and women's historical experiences. In T. J. Misa (Ed.), Gender Codes: Why women are leaving computing (pp. 213-227): Hoboken, N.J.: Wiley.

[2] Anderson, N., Lankshear, C., Timms, C., \& Courtney, L. (2008). 'Because it's boring, irrelevant and I don't like computers': Why high school girls avoid professionally-oriented ICT subjects. Computers \& Education, 50(4), 1304-1318.

[3] Ashcraft, C., Eger, E., \& Friend, M. (2012). Girls in IT: The facts. Boulder, CO: National Centre for Women \& Information Technology (NCWIT). Retrieved on 15 August 2019, from http://www.academia.edu/2283166/Girls_in_IT_The_Facts

[4] Barker, L. J., \& Aspray, W. (2006). The state of research on girls and IT. In J. M. Cohoon \& W. Aspray (Eds.), Women and information technology: Research on underrepresentation (pp. 354): Cambridge: MIT.

[5] Barron, B. (2004). Learning ecologies for technological fluency: Gender and experience differences. Journal of Educational Computing Research, 31(1), 1-36.

[6] Beyer, S. (2014). Why are women underrepresented in Computer Science? Gender differences in stereotypes, self-efficacy, values, and interests and predictors of future CS course-taking and grades. Computer Science Education, 24(2-3), 153-192.

[7] Camp, T. (1997). The incredible shrinking pipeline. Communications of the ACM, 40(10), 103-110.

[8] Camp, T. (2012). 'Computing, we have a problem...'. ACM Inroads, 3(4), 34-40.

[9] Carrington, B., Tymms, P., \& Merrell, C. (2008). Role models, school improvement and the 'gender gap'- do men bring out the best in boys and women the best in girls? 1. British Educational Research Journal, 34(3), 315-327.

[10] Carter, L. (2006). Why students with an apparent aptitude for computer science don't choose to major in computer science. ACM SIGCSE Bulletin, 38(1), 27-31.

[11] Ceci, S. J., \& Williams, W. M. (2007). Why aren't more women in science. Top researchers debate the evidence. Washington, DC: American Psych. Association.

[12] Ceci, S. J., Williams, W. M., \& Barnett, S. M. (2009). Women's underrepresentation in science: sociocultural and biological considerations. Psychological bulletin, 135(2), 218-261.

[13] Cheryan, S., Master, A., \& Meltzoff, A. N. (2015). Cultural stereotypes as gatekeepers: Increasing girls' interest in computer science and engineering by diversifying stereotypes. Frontiers in psychology, 6, Article ID 49. URL: https://psycnet.apa.org/record/2015-34083-001

[14] Cheryan, S., Meltzoff, A. N., \& Kim, S. (2011). Classrooms matter: The design of virtual classrooms influences gender disparities in computer science classes. Computers \& Education, 57(2), 1825-1835.

[15] Cheryan, S., Plaut, V. C., Davies, P. G., \& Steele, C. M. (2009). Ambient belonging: how stereotypical cues impact gender participation in computer science. Journal of personality and social psychology, 97(6), 1045-1060.

[16] Cheryan, S., Plaut, V. C., Handron, C., \& Hudson, L. (2013). The stereotypical computer scientist: Gendered media representations as a barrier to inclusion for women. Sex roles, 69(1-2), 58-71.

[17] Cheryan, S., Siy, J. O., Vichayapai, M., Drury, B. J., \& Kim, S. (2011). Do female and male role models who embody STEM stereotypes hinder women's anticipated success in STEM? Social Psychological and Personality Science, 2(6), 656-664.

[18] Cohoon, J. M., \& Aspray, W. (2006). Women and information technology: Research on underrepresentation (Vol. 1): The MIT https://econpapers.repec.org/bookchap/mtptitles/0262033453.htm

[19] Cozza, M. (2011). Bridging gender gaps, networking in computer science. Gender, Technology and Development, 15(2), 319-337.

[20] Denner, J. (2011). What predicts middle school girls' interest in computing? International Journal of Gender, Science and Technology, 3(1), 53-69.

[21] Diekman, A. B., Brown, E. R., Johnston, A. M., \& Clark, E. K. (2010). Seeking congruity between goals and roles: A new look at why women opt out of science, technology, engineering, and mathematics careers. Psychological Science, 21(8), 1051-1057. 
[22] Goode, J. (2007). If you build teachers, will students come? The role of teachers in broadening computer science learning for urban youth. Journal of Educational Computing Research, 36(1), 65-88.

[23] Gürer, D., \& Camp, T. (2001). Investigating the incredible shrinking pipeline for women in computer science. Final report-NSF project, $9812016 . \quad$ URL: https://pdfs.semanticscholar.org/548a/891c28203afc0c92092443f81daadd2219f1.pdf

[24] Gürer, D., \& Camp, T. (2002). An ACM-W literature review on women in computing. ACM SIGCSE Bulletin, 34(2), 121-127.

[25] Guzdial, M., Ericson, B. J., McKlin, T., \& Engelman, S. (2012). A statewide survey on computing education pathways and influences: factors in broadening participation in computing. $9^{\text {th }}$ conference on 'ICER', NY. URL:https://dl.acm.org/authorizestats?64304

[26] Hayes, C. C. (2010a). Computer Science: The incredible shrinking woman. In I. T. J. M. (Ed.) (Ed.), Gender codes: Why women are leaving computing (pp. 25-49): N.J.: Wiley.

[27] Hayes, C. C. (2010b). Gender Codes. In I. T. J. M. (Ed.) (Ed.), Gender codes: Why women are leaving computing (pp. 265-273): Hoboken, N.J.: Wiley.

[28] Hayes, E. (2005). Women, video gaming and learning: Beyond stereotypes. TechTrends, 49(5), 23-28.

[29] Hayes, E. (2008). Girls, gaming and trajectories of IT expertise. Beyond Barbie and Mortal Kombat: New perspectives on gender and computer games, 138-194.

[30] Hill, C., Corbett, C., \& St Rose, A. (2010). Why so few? Women in science, technology, engineering, and mathematics. Washinghton, DC: AAUW Res.Report. URL: https://www.aauw.org/files/2013/02/Why-So-Few-Women-in-Science-Technology-Engineeringand-Mathematics.pdf

[31] Hyde, J. S., Lindberg, S. M., Linn, M. C., Ellis, A. B., \& Williams, C. C. (2008). Gender similarities characterize math performance. Science, 321(5888), 494-495.

[32] Ilias, A., \& Kordaki, M. (2006). Undergraduate studies in computer science and engineering: gender issues. ACM SIGCSE Bulletin, 38(2), 81-85.

[33] Jenkins, H., \& Cassell, J. (2008). From Quake Grrls to Desperate Housewives: A decade of gender and computer games. Beyond Barbie and Mortal Kombat: New perspectives on gender and gaming, 5-20.

[34] Jenson, J., De Castell, S., \& Bryson, M. (2003). "Girl talk": gender, equity, and identity discourses in a school-based computer culture. Women's Studies International Forum, 26(6), 561573.

[35] Leslie, S.-J., Cimpian, A., Meyer, M., \& Freeland, E. (2015). Expectations of brilliance underlie gender distributions across academic disciplines. Science, 347(6219), 262-265.

[36] Liston, C., Peterson, K., \& Ragan, V. (2007). Guide to promising practices in informal information technology education for girls. Boulder, CO: NCWIT. URL: https://www.ncwit.org/sites/default/files/resources/practices_guide_final.pdf

[37] Margolis, J., \& Fisher, A. (2003). Unlocking the clubhouse: Women in computing: MIT press. [38] Margolis, J. (2010). Stuck in the shallow end: Education, race, and computing: MIT Press.

[39] Master, A., Cheryan, S., \& Meltzoff, A. N. (2014). Reducing adolescent girls' concerns about SteM stereotypes: When do female teachers matter? Revue internationale de psychologie sociale, 27(3), 79-102.

[40] Meelissen, M. R., \& Drent, M. (2008). Gender differences in computer attitudes: Does the school matter? Computers in Human behavior, 24(3), 969-985.

[41] Mercier, E. M., Barron, B., \& O'connor, K. (2006). Images of self and others as computer users: The role of gender and experience. Journal of computer assisted learning, 22(5), 335-348.

[42] Misa, T. J. (2010a). Gender codes: Defining the problem. In T. J. Misa (Ed.), Gender codes: Why women are leaving computing (pp. 3-24): Hoboken, N.J.: Wiley.

[43] Misa, T. J. (2010b). Gender codes: Lessons from history. In T. J. Misa (Ed.), Gender codes: Why women are leaving computing (pp. 251-263): Hoboken, N.J.: Wiley.

[44] Papastergiou, M. (2008). Are computer science and information technology still masculine fields? High school students' perceptions and career choices. Computers \& Education, 51(2), 594608. 
[45] Rubio, M. A., Romero-Zaliz, R., Mañoso, C., \& Angel, P. (2015). Closing the gender gap in an introductory programming course. Computers \& Education, 82, 409-420.

[46] Sáinz, M., \& López-Sáez, M. (2010). Gender differences in computer attitudes and the choice of technology-related occupations in a sample of secondary students in Spain. Computers \& Education, 54(2), 578-587.

[47] Schott, G., \& Selwyn, N. (2000). Examining the "male, antisocial" stereotype of high computer users. Journal of Educational Computing Research, 23(3), 291-303.

[48] Sieverding, M., \& Koch, S. C. (2009). (Self-) Evaluation of computer competence: How gender matters. Computers \& Education, 52(3), 696-701.

[49] Townsend, G. C. (2002). People who make a difference: mentors and role models. ACM SIGCSE Bulletin, 34(2), 57-61.

[50] Tsagala, E., \& Kordaki, M. (2007). Critical factors influencing secondary school pupil's decisions to study computing in tertiary education: Gender differences. Education and Information Technologies, 12(4), 281-295.

[51] Tsagala, E., \& Kordaki, M. (2008). Computer Science and Engineering Students Addressing Critical Issues Regarding Gender Differences in Computing: a Case Study. Themes in Science and Technology Education, 1(2), 179-194.

[52] Tympas, A., Konsta, H., Lekkas, T., \& Karas, S. (2010). Constructing gender and technology in advertising images. In T. Misa (Ed.), Gender codes: women and men in the computing professions (pp. 187-209): IEEE Press, Hoboken.

[53] Voyles, M., Haller, S. M., \& Fossum, T. V. (2007). Teacher responses to student gender differences. Paper presented at the ACM SIGCSE Bulletin, 226-230.

[54] Wang, J., Hong, H., Ravitz, J., \& Ivory, M. (2015). Gender differences in factors influencing pursuit of computer science and related fields. Paper presented at the Proceedings of the 2015 ACM Conference on Innovation and Technology in Comp. Sci. Education, 117-122.

[55] Werner, L., \& Denning, J. (2009). Pair programming in middle school: What does it look like? Journal of Research on Technology in Education, 42(1), 29-49. 